\title{
Saudi Tradition, the Culture of Dialogue, and Religious Education: a qualitative study within a Saudi University
}

\author{
Adel Abubaker Bawazeer \\ Assistant Professor of Religious Education at University of Jeddah-Saudi Arabia
}

\begin{abstract}
Developing dialogue and critical thinking ability encourages discussion between cetizins regarding the challenges and possibilities facing the community. Social dialogue can be seen as a national activity that requires citizens who are able to participate fully in dialogic activities. Education, in this case, can play a significant role in educating the public or students towards the common good and a common goal for many states across the world is to attain social cohesion through educational systems that promote moral individuals and good citizens. Thus, in recent decades, the Saudi government has sought to foster the practice of social dialogue between citizens and put forward educational policies to support that aim. This study attempted to investigate the role of the environment of higher education in promoting dialogue, in particular, in religious education modules and within its classrooms. To achieve these objectives, different qualitative methods were applied to collect the data, including semi-structured interviews with some government officials, academic teachers, and university students, as well as observations within religious education classrooms. The study found limited awareness of higher educational policy among both teachers and students. It is suggested that the Saudi Universities should play a greater role in enforcing higher education policy and have a clear vision of the policy formulation stage through to the implementation stage, in order to achieve the objectives of that policy. Hence, education in general and higher education can contribute to provide a good teaching in the frame of respecting opinions and diversities, as well as in opening the spaces within the classrooms for two-way connections among students and between students and teachers.
\end{abstract}

\section{Introduction}

Social dialogue can be seen as a national activity that requires citizens who are able to participate fully in dialogic activities. Each social dialogue involves national issues, in which citizens need to understand those aspects that are considered to be the major challenges their society faces and develop a national sense of cohesion and mutual responsibility. In last two decades, the Saudi Arabian government has focused on promoting the development of its citizens' capacity for dialogue. Given the current prominence of dialogue in Saudi Arabia, it could be argued that the principal components that will ensure the success of dialogic activities are the citizens who participate in them. Thus, opportunities are needed to enable them to engage in dialogue and exchange perspectives and ideas about the issues and topics under discussion. It is therefore important to look at ways through which the ability to engage in dialogue might be improved, by which I mean the ability to accept and respect several standpoints and to examine the different ideas through interaction with others.

The aim of the KSA government in establishing this this dialogic focus was to improve the practices of dialogue between citizens and enable them to communicate more effectively with others who embrace different ideas from the local tradition, which is strongly based on religious beliefs and practices. Therefore, religious education is seen as the principal starting point for achieving that aim. Religious education in Saudi Arabia is based on a textual knowledge that is regarded as privileged, which means there is little space for students to engage in dialogue. Thus, there is a need to investigate, empirically, the effects of dialogical activities within Religious Education (RE), particularly in HE classrooms and what these changed relationships between teachers and students might look like. This study sought to discover how the Saudi tradition impacts on the culture of dialogue within Saudi society, and specifically in the area of religious education in Higher Education (HE) institutions. This paper reports the results of a qualitative study into the practices and challenges of fostering a dialogic approach in RE classrooms in Saudi HE institutions.

Section 2 of this paper provides background information on the relevant demographic and cultural factors in the KSA and its education system, while section 3 reports how the study was conducted, and the methodology used. Section 4 presents and discusses the main findings followed by the Conclusions and Recommendations.

\section{Saudi Arabia, Education, and Religious Education}

\subsection{Saudi Arabia: population and cultural background}

In the last half century, the country has undergone major demographic change, due to the exceptionally high birth rate, together with immigration. The population of the country has grown from only around 7 million in 1974 to 34 million, according to the last census, in 2015 , about $57.5 \%$ of whom were male and only $42.5 \%$ female [17]. Particularly significant, is the 
estimated proportion of young people who were 29 years old or under, which is about 16.5 million, almost $49 \%$ of the total population. This obviously has relevance to the scale of the education system required and the importance of educating this huge number of students at both the general and higher education levels.

The Kingdom of Saudi Arabia is an Islamic state; its rules are founded on those associated with the Holy Qur'an and Sunnah. The first article of the system of government and the Shura Council (parliament) and regions provided for by establishment of the consultative body (Majlis Ash-Shura) (1992) relates to the basic laws of government, in particular in Chapter One: General Principal, which states that 'the Kingdom of Saudi Arabia is a sovereign Arab Islamic State [33]. Its religion is Islam [33]. Its constitution is Almighty God's Book, the Holy Qur'an, and the Sunna (the speech of the Prophet (Peace be Upon Him (PBUH)) [33]. As long as the Kingdom of Saudi Arabia remains an Islamic state, all transactions, regulations, the constitution, and the laws, rights, and duties must be in accordance with the Islamic approach.

Since the birth of the state, it has been evident that the Kingdom of Saudi Arabia has concentrated on a course of consultation in its policy of government. In fact, within the first section of the constitution, issued in 1926, the Saudi state is referred to as being an Islamic Consultative Royal State [13]. On the basis of that, the system of government and the Shura Council were promoted by the first king of the Kingdom, King Abdulaziz, who decided to establish a small committee, called the Consultation Council or Shura in 1928 [33]. Accordingly, a royal decree was drawn up to form the Shura Council (Parliament) and regional system in 1992, by King Fahd bin Abdul Aziz (Custodian of the Two Holy Mosques) [33].

In addition to these governmental institutions, religious institutions have also had a prominent role since the establishment of the first Saudi state in 1744[ 53], either through decision-making or in the formation of citizenship and the notion of active citizenship. Consequently, these institutions have been integrated with the state over a long period of time. This long-lasting status, coupled with cultural considerations related to the location of the two Holy Mosques in Saudi Arabia, means that the Saudis generally regard this state of affairs as advantageous to them and so they work for its continuity.

Religious feeling and morals are central to Saudi culture. The Islamic religion covers all aspects of life in the community and education is an integral part of this, valued as both as an obligation and a religious right for both males and females, as Al-Salloom [6] explains:

Islam dictates that learning is an obligation for every Muslim, man or woman. This obligation, which gives education the status of a religious duty, is the cornerstone of education in the Kingdom of Saudi Arabia. It is the foundation upon which the state builds its educational responsibilities, and in light of which, the citizen performs duties towards himself, his community, and his religion. The roots of education in Saudi Arabia therefore, go deep into the Islamic education which started in the mosque and led to the establishment of schools and universities around their pillars. (p. 37)

In an Islamic state such as Saudi Arabia, religious belief and the Islamic creed dominate the prevailing conduct in all aspects of life, and, therefore, all educational issues in Saudi Arabia are interpreted with reference to Islam. The education system in this Islamic community has a very high status. In the Qur'an (11:58), God (Allah) promotes people to seek knowledge:

\{God will raise those who have believed among you and those who were given knowledge, by degrees. \} [51]

For Muslims, knowledge and its virtues are important and enshrined in Islam, and they are brought up with this understanding and are therefore keen to learn and teach. Hence, Islamic or religious education is compulsory for all students in the school and university. In addition, according to Islamic law, males and females are separated at all levels of education, whether in school or in university buildings, and whether they are students or teaching staff.

\subsection{Why Dialogue in Saudi Arabia?}

Dialogue is an approach that is implemented in some societies with the aim of improving different aspects of the community, such as a national sense of feeling and belonging, taking greater responsibility for and involvement with governance, or the improvement of social services. In this regard, a number of national issues relate to the improvement of social services and have the status of national affiliation, with participation being a shared responsibility between government, the private sector, public organizations, academic institutions and the public [52]. All of these considerations are factors in protecting a country and its living conditions, with the result that the bodies listed above are often principal partners in dialogues within societies.

It is clear that the aims and implementation of dialogic processes will vary from country to country and will be affected by economic, political and social factors, as well as the standard of living. In the US, for example, a significant national dialogue was launched 
to improve facilities in many areas of life, such as environmental protection and online safety [9]. In a similar vein, members of the public in the UK have been engaged in group discussions as part of the national dialogue for the exchange of ideas and perspectives relating to issues regarding climate change, the environment and energy, in order to formulate policies for these challenges [16]. However, the purposes of dialogue in Saudi Arabia appear quite different in a number of respects, as Saudi society is a 'mono-cultural society' with one religion, one language and a monarchical government. The question that has to be asked, therefore, is why national dialogue is even necessary in Saudi Arabia, given that it is a mono-cultural society?

To understand the relevance and aims of dialogue in the seemingly mono-cultural nation that is Saudi Arabia, one need looks no further than the pluralism that exists between religious scholars resulting from diverse understandings of Islamic regulations and the various possible methods of implementing them. Another form of pluralism that attracts less attention is to be found in different groups of thinkers, from the conservative 'ulama' group - pragmatic, reformist and conservative - and the liberal reformers who oppose them [53].

Many important issues in Saudi society connected with its religion require dialogue before actions can be taken, in order to reach political, religious and social consensus over their wider applicability. Thus, dialogue is an important public tool for debating local issues pertaining to the role of Islam in public life, identity and modernity [26]. Moreover, diversities in understanding religious laws may require social dialogue between at least two parties, groups, or categories, belonging to and living within a given nation, regarding the possible ways in which national and religious challenges might be addressed [8]. In this sense, the function of dialogue in Saudi Arabia relates intimately to religious understanding, the field of its application, and to its effect on wider social culture.

While there may be other reasons why the government of Saudi Arabia is interested in encouraging the idea of a dialogue amongst its population, arguably the main reason is to engender a dialogue in relation to culture, with a sense of this having value in improving religious understanding and national unity [25]. Dialogue is believed to be an effective means to preserve national unity and to address violence, blasphemy and terrorism, all of which have affected the stability and security of the country [32].

In addition to this, dialogue is seen as potentially helping to improve the capacity of the populace to deal with differences in culture and civilisations around the world, giving them the ability to interact with modernity and globalisation effectively without prejudicing internal national social structure and culture. With this in mind, dialogue in Saudi Arabia is about encouraging individuals to engage in practices of dialogue as part of their daily life, providing them with a way of thinking and a clearer method of expression [41]. In this way, dialogue is also seen as making a contribution to raising citizen's qualifications for entering into active involvement, good relations and interactions that, in turn, serve to build a more confident identity [49].

The role of dialogue in fostering civic involvement is needed by any society that faces a variety of challenges [47], to create new language and concepts in social discourse, as well as new mental and social habits, and modes of living in a country. Consequently, dialogue is perceived, by King Abdulaziz Centre for National Dialogue, as being a primary qualification for future generations who will be able to protect the unity of their country and adapt to others, for the sake of achieving national, intellectual and cultural harmony [41].

In addition, a culture of dialogue is an important one in developing the relatively new idea of active citizenship in Saudi Arabia, replacing the earlier more passive conception of citizenship described above. Crick [12] notes that one of the most common features of many past societies was that they comprised leaders and followers. In the UK in the 1970s, concerns were raised about 'political illiteracy' with critics arguing that the education system did not support the forming of political concepts and active citizenship [21]. From this perspective, a new concept of 'citizenship' sought to produce active rather than passive citizens, in a process that MacDonald [31] defines as a set of dynamic practices, including political, civil, legal, cultural, and educational behaviours, which have formed over time as a result of social movements and political and intellectual forces.

Moreover, it can be argued that all communities encounter some form of social, psychological, or educational difficulties, which could be exacerbated if not be under deliberation, and which therefore require the selection of a successful method for analysis and resolution, which dialogue provides. Abdurrahman [2] suggests that individuals who feel depressed or who have limited social skills might be characterised as having excessive sensitivity and poor ability in verbal and non-verbal expression. Such individuals also have less ability to form successful relationships with others, have lower social standing amongst their friends, and tend to be less cooperative and communicative. In the case of such psychological and social problems, it would be theoretically simple for a violation to occur within the fabric of the nation, making it easier for negative culture and morals to develop, ultimately either directly or indirectly attacking community members. Hence, the concept of dialogue has grown in significance in order to maintain the unity of the nation between citizens and the convergence of their ideas, creating a peaceful 
intellectual connection, which goes beyond the limitations of the differences between them.

The Saudi government and community have become aware of the potential implications of the challenges being encountered, particularly with regard to extremist ideologies. This has encouraged the government to form various groups for intellectual dialogue with extremists, who might hold some misconceptions about religious issues. Initial indicators suggest that a degree of success is being achieved, as a consequence of the establishment of advisory committees [22]. In addition, these committees have suggested that engaging students in training courses in intellectual dialogue at different stages of their education has both a direct and indirect influence. This is because education can support a culture of dialogue and how to think in a more accommodating and appropriate way, developing a spirit of co-operation and teamwork, including activities that lead to the exchange of ideas and opinions [55]. Furthermore, having declared an obligation on individuals within society to engage in dialogic activities, the Saudi Arabian government has in turn offered support towards creating more social or educational projects and activities to spread and promote such a culture of dialogue. This can be clearly observed in, for example, the establishment of the Saudis centre of national dialogue, which is dedicated to the promulgation of cultural dialogue among members of society.

\subsection{Religious teaching in Basic Education and Higher Education in Saudi Arabia}

In Saudi Arabia, educational policies are drawn up by central government, and all curricula, syllabuses and textbooks are the same everywhere in the country. The Ministry of Education administers all public educational institutions, and its functions can be divided into two: functional responsibilities for general education at all levels of schooling and supervisory responsibilities in higher education and universities throughout the country.

Higher education was established in 1949 by the College of Islamic Studies and currently comprises twenty-four governmental universities and nine private universities, providing a wide range of programmes.

In Saudi Arabia, the higher education administrative system is highly centralised. Curricula, just in the universities, are non-unified between the universities but unified within one university. Each department and its academic staff are responsible for designing the educational modules, their syllabus and recommended reading list, with most educational modules based on one textbook. Academic staff and students have 15 weeks every term to study the textbook in full and then sit an exam based around this.
Spreading the culture of dialogue has a priority for the Saudi Government and is a key priority for the national dialogue centre that it set up [25]. Therefore, the educational curricula in general and the university curricula in particular need to find ways to engage students in dialogue, both as students and as citizens. In the light of this, it is desirable that all graduate students need to be qualified in the practice of dialogue so that they are equipped to engage in national and social activities within society. An understanding of the challenges their society faces is crucial if citizens are to deal effectively with these issues and engage in discussions about improvements and ways forward, according to the concept of citizenship and the roles ascribed to citizens within Saudi Arabia.

Citizenship is a concept that can be defined as involving two relationships: one between individual citizens and the government, and the other among individual citizens themselves, in order to unite them within a society. It is difficult to generalise, however, since citizenship is intricately related to specific cultures, social needs and governmental regimes [27], as well as to religion. Citizenship in Saudi Arabia is to a great extent shaped by the link between religion and society, and far less so by political connections.

Whilst the notion of citizenship has developed from a passive to active conception in democratic countries, in Saudi Arabia it still tends to be more passive and to focus on the criteria of 'righteousness' and belonging. However, the notion of belonging is not inconsequential, and is intrinsically related to culture, language and active participation, as well as to the sense of equality and social justice that is generated by alleviating all forms of racism and discrimination [7] [50].

When citizens or stakeholders participate in dialogic activities or in certain public social institutions, their role can shift from passive to active; thus, the properties of active citizenship have to be clear. Active citizenship describes a relationship between citizens and the state, or between one person and another, that encourages civic participation, protection of morals and respect for the law at both a local and global level [23]. In Saudi Arabia, active citizenship describes the social relationships of individuals, as imposed on them by their multiple roles in society, such as the obligations of citizenship and the exercise of rights and duties, taking into account the national, religious, ethical and behavioural aspects of society [37].

Many characteristics of active citizenship in Saudi Arabia could be linked to dialogic activities and to the wider Saudi society, including taking responsibility, religious moderation, Islamic tolerance and positive criticism [4]. Moreover, in order to achieve active citizenship, the obligations of each individual also need to be clear, since many believe that obligations 
and responsibilities are the most prominent aspects of formulating good citizenship [27].

The rights of citizens also need to be clear and protected by the government; because "without social rights, gross inequalities would undermine the equality of political and civil status inherent in the idea of citizenship" (p.17) [27]. In the Saudi context, and because the Saudi political system is an absolute monarchy in which the king is both head of state and head of government, the political rights are not the major concern for Saudis, but only social rights.

According to Saudi Arabia's educational policy, the aims of general education and higher education are concentrated on improving different abilities of students relating to daily life, society and the nation, through various courses and types of training in schools and universities [35]. Higher education aims to prepare workers for jobs and to produce citizens who are qualified and competent to perform their duties in the service of their country. Educationalists ensure the progress of their nation by offering training services and reorientation courses which enable students who are already at work to keep pace with new developments [45]. However, for cultural and political reasons, academic freedom in Saudi universities is limited [3]. Nevertheless, it can be said that engaging in dialogical activities in conjunction with the study of a university textbook may achieve the aims of the government's present policy and give students a degree of academic freedom.

Education has, I believe, a crucial role to play in promoting a culture of dialogue. Schools and universities can offer opportunities for practising dialogue, giving the students a chance to speak up and speak out about what is on their minds, increasing their motivation to interact with others and exchange ideas and conversations beyond the limits of the classroom [1]. Initiatives already undertaken suggest that students who engage in practices of dialogue will in turn develop more open-ended forms of thinking [39]. The role of dialogue in the exchange of knowledge has gradually become more important, implying a new relationship between teachers and students in a social and cooperative environment [18] [19]. There is now a need to investigate the effects of dialogical activities and what these changed relationships between teachers and students might look like. This study aims to do just that.

Language is the most fundamental variable in dialogue. As Arabic is the formal and first language of Saudi Arabia, those who participate in dialogical practices must be well versed in this language [36]. In addition, Brown [10], from a classroom perspective, comprehensively listed the language skills necessary for successful dialogue, and argued that this requires fluency, phonological clarity, thinking strategies and being able to produce meaningful responses.

Al-Saied [5] suggests another set of features required in dialogue, including analysis, inference, understanding, memorisation and perception. Others divide language skills into two groups: the process of language decoding into meaningful units and the process of attributing meaning, in the move from an abstraction to something that is both clear and understood [10][40]. Dialogue also requires clarification of the meanings and terms used.

In addition to cognitive and speech skills, the capacity to take part in dialogue also includes behavioural expression and ethics. According to AlSaied [5] behaviour and ethics rely on two main processes: gaining information and developing the necessary ethical capacities to perform actions that are orientated to attaining the 'good'. He, therefore, emphasises that the virtuous behaviour of each person is expressed by his/her own behaviour individually, based on their level of knowledge, as well as their embodiment of moral rules and capacities. It is clear that dialogue is underpinned by ethics and morals, in addition to the other elements identified above.

Based on the aspects of dialogue described above, a list of capacities has been drawn up which are thought to promote successful and effective dialogue. Rosenbaum [43] identifies listening and speaking as key aspects. In terms of listening, he suggests the following sub-elements: dialogue participants need to be patient, aware of meaning in language, be able to indicate and organise words and listen for structures such as stories, reasons and goals, rather than merely listening for facts, for example. Rosenbaum [43] also underlines the importance of silence as a means to both understand and absorb the feelings of the speaker, as well as to connect the elements of the spoken sequence without interruption. In speaking, the asking of questions is most important, ensuring that the understanding of the message is clear, although other speaking capacities include different spheres relating to conflict, criticism and emotional control.

The possession of these capacities and knowledge of how to translate them into practice successfully is necessary to participate in the field of dialogue. In this regard, there is potential connection with the work of MacIntyre in so far as opportunities for the exercise of dialogical capacities are necessary for the collective pursuit of common goods. Education, in these terms, far exceeds a limited concern with acquiring skills for the workplace: rather, the role of education is to provide spaces for a much broader set of educational practices [30]. Promoting a culture of dialogue through education in general and religious education in particular would encourage students to present their respective opinions and promote diversity and pluralism through respect for and the acceptance of different points of view. These points will be considered in more detail in the section. 


\subsection{Dialogue within Religious Education Classrooms}

Religious education dominates the educational system in Saudi, with religious content present at all educational stages (pre-school, primary school, intermediate school, high school, higher education). Thus, for example, nearly one-third of primary school sessions per week are based on the subject of religious education [20], and courses in religion are also compulsory for all university students [15], regardless of their academic specialism [35]. Hence, the educational policy of Saudi Arabia has foregrounded the place of religion in designing the current policy and all stages of the educational system. Thus, the ultimate objectives of education in Saudi Arabia are explicitly described in the following terms:

To have the student understand Islam in a correct and comprehensive manner. To plant and spread the Islamic creed, and to furnish the student with the values, teaching, and ideals of Islam. To equip him with various skills and knowledge, and to develop his conduct in constructive directions. To develop the society economically, socially, and culturally, and to prepare the individual to become a useful member in the building of his community (p. 5) [35].

This statement shows that, whilst the first two purposes of education (in terms of socialization and qualification) are acknowledged in the Saudi context, these are set in an overall religious framework. This religious framing of education is, moreover, specifically aligned with fundamental Islamic principles including the belief in Allah as God, in Islam as the Saudi religion, and in the message of the Prophet Mohammed (peace be upon him), and the complete Islamic characterization of the universe, humanity, and life itself (p.2) [35]. Such a framing, however, raises a question as to the place of dialogue in Saudi education, and, related to this, the place of subjectification, given the clearly described religious and educational purpose.

Gaining Islamic knowledge, then, has a significant role in religious education in the Saudi educational system. Therefore, memorizing large parts of the Qu'ran and Hadith, its interpretation and the translation of such knowledge of Islamic tradition into the practice of everyday life is at the core of the religious education curriculum. However, in recent years concern has been expressed that an exclusive focus upon the knowledge and memorization of a text as the main purpose of religious education can lead to neglecting other educational practices, i.e. those practices that become desirable if the purpose of religious education is to include acknowledging difference and engaging with different points of view, and opportunities for subjectification. In other words, a broader understanding of purpose in relation to religious education may lead to the promotion of other elements, such as the practice of dialogue, together with opportunities for individuals to develop their own distinctive response to the matters in hand. This call for a broader understanding of educational purpose has also come from an acknowledgement that the younger generation of Saudis perceptibly lacks a number of capacities that are especially valued by the private sector [15], and these include the dialogical practices mentioned above.

As identified above, classroom activities are an essential part of developing dialogic practices and therefore, classroom exercises to improve students are a priority. In this regard, Johnson [24] argues that some teachers "have become so involved with delivering the curricula that we have failed to acknowledge how we deliver the curricula" (p. 3). Dialogue in the classroom should become a more frequent feature because it "allows students to reflect on their own thinking, to detail their own understanding, to listen to each other's ideas and to ask questions for clarification" (p. 6) [14]. Group work or cooperative learning can also contribute to encouraging dialogue within the classroom and generally encouraging students to engage more actively in learning [44], through speaking and articulating ideas, asking critical questions and thinking in depth when it comes to answering them [54].

In addition, classroom communication helps to ensure that every student is exposed to a range of ideas, by making these ideas the focal points of questions and enabling students to explore them through dialogue [14]. By offering syllabuses that have been designed to develop their dialogic practices and related capacities [38], education encompasses the overall development of each student. University teachers "can dramatically influence the extent and quality of learning for all students" (p. 1) [29], opening new spheres for students to practice many skills such thinking, analysing, and criticising through asking questions and through the practice of dialogue. However, traditionally, the transfer of knowledge and experience from generation to generation has been one of the most important aims of schooling in many societies. Within such a paradigm, the focus of teachers tends to be oriented primarily towards knowledge, which students accept and memorise, as opposed to a focus on promoting broader educational practices within classrooms. However, lack of opportunities for practising dialogue together with weakness in knowledge as to how to conduct dialogue and classroom communication, has influenced the relationship between teacher and student, leading to some students rejecting the teaching being offered to them. This has resulted in some students not being 
able to fully deal with the information provided, instead avoiding or resisting it, and not being actively involved in the classroom [42].

Asking questions is an important way that teachers can promote dialogue in the classroom. Schihalejev [46] analysed a group of questions that had been provided by teachers and observed the students' contributions and their interactions. In analysing his observations, he [46] divided questions into three groups:

\section{The first group, 'closed questions', required memorised facts to be recalled. There is a clear border between right and wrong answers... The second group, 'half-open questions', focused on understanding the material and could have more than one right answer, but still there is a border between right and wrong answers... The third group, open questions, consisted of questions where a listener cannot say if the answer is correct or not. Instead, students reflected upon their opinions, preferences, or cited examples from their lives. (p. 282)}

Schihalejev [46] found out that when teachers asked closed questions or half-open questions "the readiness to cooperate and the interest of pupils increased... or expected memorisation or finding the right answer from worksheets". On the other hand, when open questions were asked, that required student's opinion or preferences, he found that students were puzzled and seemed 'switched off' and he "did not find any response from students, they either refused to answer or said that they do not have any opinion... that information they have is too superficial and they need to know more".

In the wake of a succession of developments in education studies in recent decades, teaching methods and the subsequent learning achievements of students have improved considerably in many countries, with teachers also becoming more aware of how to provide effective teaching and classroom management [29]. As a result, dialogue has become a more frequent feature in the classroom, as it can have a deep impact in convincing students of the significance of new knowledge, to avoid the problems identified in Schihalejev's study.

Many teaching methodologies are applied in the classroom in order to stimulate dialogue. Discussion groups or cooperative learning and dialogue strategies are core aspects of this methodology, leading to interaction and dialogue with peers and producing the quickest, longest lasting and most transferable learning outcomes [28]. The dialogue strategy is also a successful technique for fostering the involvement of teaching with communication, enabling students to gain access to truth, intellectual development and social exploration, through the use of their personal skills [48]. Teaching aids also contribute to increasing dialogue in the classroom. Teachers can introduce new forms of knowledge by means of these aids, and they can also encourage students to play a more active and positive role.

Whilst all the above teaching methods are potentially effective ways of facilitating the engagement between teachers and students, leading to the acquisition of both knowledge and educational capacities, in practice different religious and national issues seem to be of particular importance among people of different countries. Different contexts will, therefore, tend to refract dialogical practice differently according to these differing priorities. If dialogue is to be promoted within Saudi higher education it would appear that new teaching methods need to be implemented in universities, to encourage the discussion of the particular contemporary community issues that have been included in the course syllabus. According to Bawazeer [8], Saudi teachers are both qualified and prepared to implement different methods in order to improve the capacities for national dialogue in Saudi Arabia.

\section{Methodology}

In order to understand the purposes of dialogue within Saudi society and how religious education can play its role within university classrooms in spreading the culture of dialogue a qualitative methodology has been applied in this study. This because the qualitative research description and reporting [11]. A qualitative methodology was deemed to be the most appropriate approach for this project, as it attempts to investigate the case of the Saudi culture within its context and society and the impact of that on religious education in the university.

Following the qualitative approach [11], the methods of collecting data in this study were:

a) individual face-to-face semi-structured interviews with Saudi Government officials, to understand the situation of dialogue in the culture of Saudi Arabia; and

b) semi-structured interviews by telephone with male and female teachers and students who teach and attend religious education modules in the university; and b) open classroom observation of the religious education modules.

This project was implemented in one of the Saudi universities and faculties where the religious education modules are taught.

\section{Findings and Discussions}

After analysing the data, it would appear that if a culture of dialogue is to be spread, this has to take place within the context of understanding Islamic laws that continue to inform Saudi society. The findings show that together with respecting and 
adhering to Islam and its constants, maintaining national unity and the political system are considered to be the primary pillars of Saudi tradition. In this regard, there are restrictions on dialogue within Saudi society that were noted by respondents. Although the Saudi Government, provides a number of spaces for dialogue, whether formally in the Shura Council, or informally by establishing the King Abdulaziz Centre for National Dialogue, it appears that debating Islamic constants or political issues, for example, is not acceptable to Saudi citizens. This confirms the need for a culture of dialogue to be developed within the Saudi community through the educational system.

Perhaps the most striking finding was the disconnect between the lack of acceptance of diversity and other's opinions which was reported and the overt encouragement within the Islamic tradition to engage in dialogue and accept others in all their diversity. In this latter regard, it should be pointed out that the King Abdulaziz Centre for National Dialogue seeks to develop a more balanced discourse, one that accepts pluralism and diversity while simultaneously maintaining the social fabric.

The participants' answers illustrated that Saudi society needs the culture of dialogue in order to face the challenges posed by the traditions of Saudi society. Examples mentioned included the need for dialogue for the following purposes: enhancing the sense of national responsibility and unity, accepting the diversity of the tribes and tackling racism, promoting and protecting diversity and pluralism, reducing intellectual conflicts and respecting others and their opinions, strengthening the family and the social fabric, and dealing with the challenges and opportunities of modern technology, devices and platforms.

Respecting religion and the tribal cultures are considered the main characteristics of the Saudi traditions. Changing such agreed traditions in a society is difficult and may lead to a conflict but having a deep and calm dialogue about the practices of these traditions is nevertheless required. This means that, if the society is to become renewable, interactive and dynamic, there will be a need for extensive interactions with others, even though this is both difficult and complex in practice. Otherwise, the tradition will remain limited in its scope, singleminded and reflecting a single consciousness. In the Saudi context, this can lead to arrogance in making judgments about others, their religion, thoughts and Islamic faith, or to accusing a Muslim of being a nonMuslim, leading to forms of intellectual extremism. This can not only affect the whole country but also may be reflected at a global level at one end and a very local level, such as within individual families, at the other end.

In terms of creating an environment more conducive to dialogue within the Saudi tradition, most respondents appeared to hold the view that understanding the concept of dialogue would decrease the possibility of conflict and improve practices. In addition, it could reduce the gap between different opinions that may affect individual relationships. Another way of reducing negative attitudes, as the participants assured, is by disseminating the virtue of moderation through practising dialogue. Moderation would assist everyone to become aware that he/she can remain in his/her self-consciousness as well as being open and listening to others towards reaching a point of consensus.

As explained above, the Saudi Government has drawn up an educational policy to promote the culture of dialogue within Saudi society in the different educational stages, including higher education, which is the focus of this study. However, although this policy is available for everyone to read, there was a lack of awareness of this aim among the respondents and, hence, limited implementation of its goals and purposes. Respondents also reported that abilities in relation to dialogue, are undeveloped in the population in general. This means that some of the goals of higher education, as set out in the higher education policy, have yet to be achieved. Evidence of this failure can be seen in the lack of specialised knowledge and job skills among university graduates. Therefore, practising the activities of dialogue at universities are required to help students to acquire independence of thought, which will then enable them to reflect on their broader social role and on communicating to the public. Hence, the university environment must have space for diversity and teachers have to take their roles in motivating students to read books, promoting diversity and respecting pluralism. Through these Islamic and Saudi traditions, the university environment and the reasons for needing dialogue in religious education, religious education in the university provides the opportunity for philosophical dialogue and consequently, needs to be reconstructed on the basis of moderation, pluralism and respect for others and their opinions.

This study used a number of methods to investigate empirically the dialogue practices within university classrooms, including classroom observations. The results of this part of the study found considerable variations in the extent to which teachers and students engaged in dialogue and dialogic practices within the classroom. While teachers and students seemed to be aware of the importance of dialogue - and appeared to share an understanding of its meaning too - practices in the classroom did not generally reflect this.

Students identified three main factors that discouraged them from engaging in dialogue: psychological factors, such as fear and lack of confidence; lack of practical experience in engaging in dialogue within the classroom; and lack of knowledge about the subject under discussion. When teachers seek to promote a culture of dialogue, these 
three factors should be taken into account. The core role of the teacher in this regard is promoting and motivating students to become involved in dialogue, creating opportunities for students to speak freely and providing a safe environment in which students can express their opinions. Moreover, teachers need to use teaching methods that will increase student motivation and create an atmosphere of active learning, self-learning, and knowledge exchange, instead of the traditional teaching methods focused upon alignment with, and memorization of, a preestablished text, which was heavily criticised by all participants.

\section{Conclusion}

This study has highlighted the importance of dialogue in the educational system generally and in religious education in particular, from both theoretical and empirical perspectives. This involves implementing an appropriate understanding of dialogue in religious education in Saudi universities. Although this approach is supported by the country's higher educational policy, this study found worryingly low levels of awareness of this policy among both teachers and students. It is difficult to see how the purposes of any policy can be fulfilled if key players are unaware of it. Therefore, I argue that the Saudi University should play a greater role in enforcing higher education policy and have a clear vision of the policy formulation stage through to the implementation stage, in order to achieve the objectives of that policy.

The need for effective dialogue is critical because the Saudi community is highly homogenous and any diversity is not immediately apparent, as all Saudis believe in one religion (Islam), speak one language (Arabic), and have a monarchical system with no political parties. So, at first sight, it is hard to identify any kind of diversity. However, it became clear that there are, notwithstanding these points of unity, considerable points of difference within the culture too. In this connection, there are a number of social and intellectual challenges in the Saudi community that need to be addressed and the promotion of dialogue, as shown in the findings. Based on this study, the following challenges were identified: applying religious teachings, adjusting to contemporary changes, ambiguities associated with the concept of dialogue, judging others on their beliefs and categorising them based on their views.

Education has a crucial role to play in promoting a culture of dialogue. Overall, this study has found that the design and provision of a comprehensive educational curriculum to promote dialogue is urgently needed, one that takes into account the religious and national frames of reference in the Saudi context and the challenges and requirements of the Saudi community. It is also necessary within educational contexts to focus on the exchanging of roles between teachers and students within the classrooms where dialogue takes place. This can help provide some of the conditions necessary for ensuring a 'good' education, which aims at socialisation and professional preparation, rather than focusing on merely transferring knowledge from teachers into students in the style of one-way communication.

\section{References}

[1] Abdul Hameed, J., 2000. Teaching and Learning Strategies. Cairo: Dar Arab Thought.

[2] Abdulrrahman, M., 1998. Studies in Phycological Health. Cairo: Dar Quba.

[3] Alamri, M., 2012. Higher Education in Saudi Arabia. Journal of Higher Education Theory and Practice, pp. Volume 11, issue 4, 88-91.

[4] Al-Hindi, S. and Dalasha, A., 1990. Citizenship Education in Jordan. Amman: Dar Al-Fikr.

[5] Al-Saied, F., 1998. Psychology Foundations of Growth from Childhood to Old Age. Cairo: Dar Arabic Thought.

[6] Al-Salloom, H., 1989. The System and Development of General Education and its Equivalent Programmes in the Kingdom of Saudi Arabia. Washington D.C.: Saudi Arabian Cultural Mission.

[7] Anderson, K. and Taylor, A., 2005. Exclusionary Politics and the Question of National Belonging Australian Ethnicities in 'Multiscalar' Focus'. Institute for Culture \& Society Pre-Print Journal Articles, pp. Volume 5, Number 4, p. 460-485.

[8] Bawazeer, A., 2010. The Role of an Islamic Education Teacher in Developing Secondary Students' National Dialogue Abilities. Riyadh: King Abdulaziz Centre for National Dialogue.

[9] Beierle, T., 2002. Democracy On-Line: An Evaluation of the National Dialogue on Public Involvement in EPA Decisions. Washington D.C: Resources for the Future.

[10] Brown, D., 2001. Teaching by Principles: An Interactive Approach to Language Pedagogy. New York: Addison Wesley Longman.

[11] Cohen, L., Manion, L and Morrison, K., 2011. Research Methods in Education. Oxon: Routledge.

[12] Crick, B., 2000. Essays on Citizenship. London: Continuum.

[13] Dahlan, A., 1985. The Internal Politics Study of the Kingdom of Saudi Arabia. Jeddah: Dar Al-Shroq.

[14] Dufresne, R., Gerace, W., Leonard, W., Master, J. and Wenk, L., 1996. Class talk A Classroom Communication System for Active Learning. Journal of Computing in Higher Education, pp. Volume 7, Issue 2, p. 3-47.

[15] Duthel, H., 2015. The Social Networks Revolution. (n. p.): IAC Society.

[16] Fudge, S. and Peters, M, 2011. The National Dialogue on Behaviour Change in the UK Climate Debate: an assessment of responsibility, agency and political dimensions. Sustainability, pp. Volume 3, Number 6, 789-808.

[17] General Authority for Statistic, 2020. [Online] Available at: https://www.stats.gov.sa/en (Access Date: 15 Mar, 2019). 
[18] Grudens-Schuck, N., 2003. No Beginners: Teaching Participation at the Graduate Level. PLA notes, pp. Volime 48, issue 12, p. 11-14.

[19] Haggis, T., 2006. Pedagogies for Diversity: retaining critical challenge amidst fears of 'dumbing down'. Studies in Higher Education, pp. Volime 31, Issue 5, p. 521-535.

[20] House, K., 2012. On Saudi Arabia : Its People, past, Religion, Fault Lines and Future Society. New York: Alfred A. Knopf.

[21] Huddleston, T., 2006. 'From Political Education to Political Literacy: equipping young people for life in a more genuine democracy'. In: Developing Citizens. London: Hodder Murray.

[22] International Centre for Political Violence and Terrorism Research (ICPVTR), 2010. Saudi Initiative in Countering Terrorism. Singapore: Nanyang Technological University.

[23] Jochum, V., Pratten, B. and Wilding, K., 2005. Civil Renewal and Active Citizenship a Guide to the Debate. London: National Council for Voluntary Organization.

[24] Johnson, M., 2019. Communication in the Classroom. [Online] http://www.eric.ed.gov/PDFS/ED436802.pdf (Access Date: 2 Feb, 2019).

[25] King Abdulaziz Centre of National Dialogue, 2019. [Online] http //www.kacnd.org/eng/ (Access Date: 3 Mar, 2019)

[26] Kraidy, M., 2009. Reality Television, Gender and Authenticity in Saudi Arabia. Pennsylvania: University of Pennsylvania, Annenberg School for Communication.

[27] Lister, R., 2003. Citizenship Feminist Perspective. Basingstoke: Palgrave Macmillan.

[28] Long, G., Vignare, K., Rappold, R. and Rappold, J., 2007. Access to Communication for Deaf, Hard-of Hearing and ESL Students in Blended Learning Courses. International Review of Research in Open and Distance Learning, Volume 8, Issue 3, p. 1-13.

[29] Maathuis, M., 2019. Effective Teaching and Classroom Management is about whole Child - and whole School Development for Knowledge, Skills and Human Values. [Online] http //toolkit.ineesite.org/toolkit/ INEEcms/uploads/1088/Effective_teaching_and_ classroom_management.pdf (Access Date: 18 Feb, 2019).

[30] MacAllister, J., 2018. Utopianism of the Present: MacIntyre on education and the virtue of hope. International Critical Thought, Volume 9, Issue 3, p. 436-446.

[31] MacDonald, L., 2003. Traditional Approaches to Citizenship Education, Globalization, towards a Peace Education Framework. PhD thesis, Halifax: Dalhousie University.

[32] Mahfooth, M., 2004. Political Reform and National Unity. Casablanca: Cultural Western Centre.

[33] Majlis Ash-Shura, 2016. The Basic Low of Government', Saudi Arabia. [Online] http //www.shura.gov.sa/wps/wcm/connect/Shura En/internet/Laws+and+Regulations/The+Basic+Law+ Of+Government/ (Access Date: 11 Mar, 2019).

[34] Ministry of Culture \& Information, 2016. The Saudi Arabia Information Resource. [Online] https://www.moci.gov.sa/ar-sa/Pages/default.aspx (Access Date: 1 Mar, 2019).

[35] Ministry of Education, 1995. Educational Policy In Saudi Arabia. Riyadh: Ministry of Education.
[36] Moauad, K., 2003. Educational Psychology Science Its Foundations and Applications. Alexandria: Alexandria Center for Book.

[37] Morsi, M., 2009. Foundations of Education. Cairo: Books World.

[38] Nemec, P., McNamara, S. and Walsh, D., 1992. Direct Skills Teaching. Psychosocial Rehabilitation Journal, pp. Volume 16, Issue 1, p. 13-25.

[39] Nicholas, C. and Bertram, C., 2001. Theory and Research on Teaching as Dialogue. In: Handbook of research on teaching. Washington DC: American Educational Research Association, pp. 1102-1121, 4th Edition, Virginia Richardson (Eds.).

[40] Peterson, P., 1991. A synthesis of methods for interactive listening. In: Teaching English as a Second or Foreign Language. 2nd edition, New York: Newbury House, pp. 106-122.

[41] Public Relations and Information Department, 2005. Manual of Definitions. Riyadh: King Abdul Aziz Centre for National Dialogue.

[42] Richmond, V., 1990. Communication in the classroom Power and Motivation. Communication Education, pp. Volume 39, p. 181-195.

[43] Rosenbaum, T., 2005. Effective Communication Skills for Highway and Public Works Officials. New York: Cornell Local Roads Program.

[44] Ruel, G. and Bastiaans, N., 2003. Free-riding and Team Performance in Project Education. International Journal of Management Education, pp. Volume 3, Issue 1, p. 26-37..

[45] Saleh, M., 1986. Development of higher education in Saudi Arabia. Higher Education, pp. Volume 15, p. $17-$ 23.

[46] Schihalejev, O., 2009. Dialogue in Religious Education Lessons - Possibilities and Hindrances in the Estonian Context. British Journal of Religious Education, pp. Volume 31, Issue 3, p. 277-288.

[47] Spano, J., 2001. Public Dialogue and Participatory Democracy: The Cupertino Community Project. New Jersey: Hampton Press.

[48] Stables, A., 2003. Learning, Identity and Classroom Dialogue. Journal of Educational Enquiry, pp. Volume 4, Issue 1, p. 1-18.

[49] Stewart, J. and Zediker, K., 2000. Dialogue as tensional, ethical practice. Southern Communication Journal, pp. Volume 65, p. 224-242.

[50] Tambini, D., 2001. Post-national citizenship. Ethnic and Racial Studies, pp. Volume 24, Number 2, p. 195217.

[51] The Qur'an, 2013. The Qur'an: With Surah Introductions and Appendices (English Translation: Saheeh International Translation). Birmingham: Maktabah Booksellers and Publishers.

[52] U.S. Department of Homeland Security, 2010. Quadrennial Homeland Security Review Report. Washington D.C: Homeland Security.

[53] Wagemakers, J., Kanie, M. and Geel, A, 2012. Saudi Arabia Between Conservatism, Accommodation and Reform. The Hague: Netherlands Institute of International Relatio 'Clingendael'.

[54] Watkins, R., 2019. Groupwork and Assessment. [Online] https://www.economicsnetwork.ac.uk/hand book/printable/groupwork.pdf (Access Date: 4 May, 2019) 
Journal of Information Technologies and Lifelong Learning (JITLL), Volume 3, Issue 1, 2020

[55] Wazan, S., 1993. Teaching at the School of Prophecy, Series of the Right Call. Makkah: Muslims' World League. 